\title{
Life sciences and biotechnology in China
}

\author{
Zhu Chen ${ }^{1,2, *}$, Hong-Guang Wang ${ }^{3}$, Zhao-Jun Wen ${ }^{2}$ and Yihuang Wang ${ }^{2}$ \\ ${ }^{1}$ Chinese Academy of Sciences, 52 San Li He Road, Beijing 100864, People's Republic of China \\ ${ }^{2}$ State Key Laboratory of Medical Genomics, Shanghai Institute of Hematology, Rui-fin Hospital, \\ School of Medicine, Shanghai fiao Tong University, 197 Rui-fin II Road, \\ Shanghai 200025, People's Republic of China \\ ${ }^{3}$ China National Center for Biotechnology Development, Ministry of Science and Technology of China, \\ B7, ZaofunMiao, Beijing 100081, People's Republic of China
}

\begin{abstract}
Life science and biotechnology have become a top priority in research and development in many countries as the world marches into the new century. China as a developing country with a 1.3 billion population and booming economy is actively meeting the challenge of a new era in this area of research. Owing to support from the government and the scientific community, and reform to improve the infrastructure, recent years have witnessed a rapid progress in some important fields of life science and biotechnology in China, such as genomics and protein sciences, neuroscience, systematics, super-hybrid rice research, stem cell and cloning technology, gene therapy and drug/vaccine development. The planned expansion and development of innovation in related sectors and the area of bioethics are described and discussed.
\end{abstract}

Keywords: life science; biotechnology; biological science

\section{INTRODUCTION}

Being one of the primal centres to see the rise of human civilization, China has a long history of applying a knowledge of life and traditional biotechnology to daily practice. About 2 years ago, a group of scientists from the United States, China and Germany found ancient chemical evidence of a prehistoric fermented beverage in pottery jars from the Early Neolithic village of Jiahu in Henan Province in China (McGovern et al. 2004). This now enables the fermented beverage to be traced back as far as 7000 BC and reveals how Chinese beveragemaking developed over the millennia. Numerous similar studies have shown that traditional biotechnology was flourishing throughout history and is still important in modern Chinese society. China is the top producer of vinegar, soy sauce, beer and alcohol using traditional fermentation technology in the world. Traditional Chinese medicine (TCM) is another great achievement of the ancient Chinese life sciences. About 900 years ago, the Chinese people started to use a primal live vaccine for the prevention of smallpox. The technology was popularized in the 1700s, and recorded in the book of 'Yi Tong (Comprehensive Medicine)' written by Zhang $\mathrm{Lu}$ in the Qing dynasty (1796). The great success of our ancestors spurs on new generations of Chinese biologists and biotechnologists to catch up with the advances in modern life sciences and biotechnologies.

Over the past 20 years, life sciences and biotechnology have brought a promising prospect of a worldwide growth in such areas as medicine, the pharmaceutical industry, agriculture and environmental protection, etc. As a field of great importance

* Author for correspondence (zchen@stn.sh.cn).

One contribution of 14 to a Theme Issue 'Biological science in China'. to the whole of society, which could change the pattern of future industry and economy, life sciences and biotechnology have been drawing increasing attention from every country of the world, including China.

China is one of the countries with the richest biological resources and diversities in the world. It is the only country on earth where there are unbroken connections between tropical, subtropical, temperate and boreal forests and this has led to the formation of rich plant associations and biological diversities rarely seen elsewhere in the world. According to the statistics, China has approximately $10 \%$ of the world's biological resources. Some 31000 plant species are native to China, representing nearly one-eighth of the world's total plant species, including thousands found nowhere else on earth. In addition, 200000 species of known animals and 30000 species of described micro-organisms are found in China. Therefore, China is praised as the 'Mother of the World Garden'. So far, 0.32 million idioplasmatic units of crops have been collected. Recent efforts to collect DNA samples and/or cell lines from the 56 ethnic groups of the Chinese population have also made major progress. This has given China tremendous resources for developing life sciences and biotechnology.

Meanwhile, China, as a developing country with a population of nearly 1.3 billion, faces great challenges in terms of population growth, health care and agricultural development. The prevention and treatment of various health-threatening diseases needs to be improved. While a family planning policy will have to be implemented long-term, the problem of old age is looming large with $10 \%$ of the population over 60 years old. In addition, despite much progress being made, China's agricultural development is still rather poor in efficiency and quality, thereby exerting huge pressure on natural resources and the eco-environment. The recent pressure on energy 
supplies also calls for the application of biotechnology to renewable energy in the future. Hence, the development of life sciences and biotechnology is of great significance to the sustainable development of China and the building-up of a harmonious human-centred society.

\section{KEY DEVELOPMENT AREAS AND ACHIEVEMENTS OF LIFE SCIENCES IN CHINA}

The fact that China is a developing country determines that its investment priorities in science and technology should mainly target major social problems. Therefore, emphasis must be laid on the strategic balance between national goals and science frontiers, an integration of basic research and application-oriented investigation, and the accomplishment of limited but achievable goals and of breakthroughs in some key areas (Jiang 2000). With growing support from the government and the efforts of the Chinese science community, breakthroughs have been made in some priority areas, including genomics, bioinformatics, identification of genes related to major diseases, molecular biology and biochemistry, cell and developmental biology, neurobiology, systematics and coevolution of animals and plants.

\section{(a) Genomics}

In genomics, one of the frontiers of the life sciences, China has made some significant achievements. Chinese scientists undertook and completed $1 \%$ of the International Human Genome Sequencing Project, mainly on a region of $30000000 \mathrm{bp}$ in the short arm of chromosome 3 (Lander et al. 2001). In addition, Chinese scientists have published about 1000 fulllength cDNAs of novel genes in the public database, as a major contribution to the gene discovery effort of the Human Genome Project.

The completion of a draft sequence of the rice genome (Oryza sativa L. ssp. indica) is a milestone achievement of China's genomics research. A paper entitled 'A draft sequence of the rice genome', was published in Science in April 2002 (Yu et al. 2002). It was a major scientific breakthrough of that time. In November 2002, another group in China published the complete sequence of chromosome 4 of japonica strain rice in Nature (Feng et al. 2002b). It was an integral part of the International Rice Genome Sequencing Project, which was finished in 2005. In December 2002, Chinese scientists again took the lead in completing the fine map of the whole indica rice genome. More recently, a great number of rice functional genes, such as the one involved in rice tillering, were characterized in China (Li et al. 2003).

In microbial genome sequencing, China has also made breakthroughs. So far, Chinese scientists have completed the full genome sequencing of six microbes, including the pathogen Leptospira interrogans (Ren et al. 2003). During the course of the severe acute respiratory syndrome (SARS) epidemic in China, a Chinese consortium was organized to work on the molecular evolution of the SARS coronavirus (Song et al. 2005). Sixty-one SARS coronavirus genomic sequences, derived from the early, middle and late phases of the SARS epidemic, were analysed together with two viral sequences from palm civets. The result strengthens the argument for an animal origin of the human SARS epidemic.

\section{(b) Biomedicine}

With the improvement of people's living standards, increasing attention has been paid to health and life quality, and therefore, biomedicine. Research institutions working in biomedicine or related areas include the Chinese Academy of Sciences (CAS), the Chinese Academy of Medical Sciences, the Chinese Academy of Military Medical Sciences and various medical schools of research universities.

China started research into protein denaturalization in the 1920s. In 1965, China synthesized bovine insulin, the first protein molecule ever synthesized with biological activities (Kung et al. 1965). In the 1970s, Chinese scientists obtained the high-resolution three-dimensional structure of insulin (The Peking Insulin Structure Research Group 1974). Since the 1990s, mostly promoted by genetics and genomics, China's biomedical research has made remarkable progress and has provided the theoretical basis for the prevention, diagnosis and treatment of diseases, and the designing and development of drugs.

In recent years, Chinese scientists have identified a series of disease-conducive genes by bringing the advantage of human genetic resources into full play. The sequential breakthroughs include: gene cloning and functional research in acute promyelocytic leukaemia, which is a new model of differentiation therapy for human cancer (Wang \& Chen 2000); identification of a batch of genes responsible for monogenic diseases, such as hereditary high-frequency hearing impairment (Xia et al. 1998); and familial atrial fibrillation (Chen et al. 2003a). The loci of susceptibility to type II diabetes (Du et al. 2001; Luo et al. 2001), essential hypertension ( $\mathrm{Xu}$ et al. 1999; Zhu et al. 2001) and nasopharyngeal carcinoma (Feng et al. 2002a) have all been precisely located.

In the field of biochemistry, a new defensin-like protein expressed in the epididymis of the rat was found and its natural anti-virus function confirmed ( $\mathrm{Li}$ et al. 2001). This work showed, for the first time, that the epididymis has its own defensive immune system. With regard to protein structure and function, scientists revealed that the protein disulphide isomerase functioned not only as an enzyme but also as a chaperone in protein folding (Wang 2002). In 2002, as a world leader, China initiated the Liver Proteomics Project in an attempt to identify the structure/function of all proteins produced by this organ and to get a better understanding of various liver diseases ( $\mathrm{He} 2006$ ). Structural genomics has seen a boom in China as well. A good example is the recently discovered threedimensional structure of the 3C-like protease of the SARS virus that is considered to be the major drug target (Yang et al. 2003).

The fact that signal transduction abnormalities lie at the heart of cancer, autoimmunity and other major diseases has fuelled a massive scientific effort aimed at the identification of and functional research into the signalling proteins that regulate the various behaviours of individual cells, tissues and organ systems. Furthermore, drug discovery based on the modulation of 
signalling proteins will prove beneficial in the prevention and treatment of major human diseases, including cancer, chronic inflammatory diseases and neurodegenerative syndromes. In 2004, Chinese scientists found that $\beta$-arrestin 2 directly interacts with $\mathrm{I} \kappa \mathrm{B} \alpha$ (an inhibitor of $N F-\kappa B$, the key molecule in innate and adaptive immunity) and mediates a crosstalk between $\beta 2 \mathrm{AR}$ and $\mathrm{NF}-\kappa \mathrm{B}$ signalling pathways. This study may present a novel mechanism for regulation of the immune system by the sympathetic nervous system (Gao et al. 2004). In 2005, scientists revealed the novel function of $\beta$-arrestin 1 as a cytoplasm-nucleus messenger in G-protein-coupled receptor (GPCR) signalling and elucidated an epigenetic mechanism for direct GPCR signalling from the cell membrane to the nucleus through signal-dependent histone modification (Kang et al. 2005).

Research on stem cells is one of the most exciting frontier areas of the life sciences. So far, Chinese scientists have successfully conducted human somatic cell nuclear transfer, established a human or hybrid embryo stem cell system (Chen et al. 2003b) and mastered methods allowing in vitro human embryonic stem cell differentiation towards neural and muscle cells.

Recent years have witnessed remarkable progress in neuroscience and cognitive science research in China. Following the proposition of a topological visual-form perception hypothesis (Chen 1982), recent work on visual systems using functional magnetic resonance has provided biological support for the concept (Zhuo et al. 2003). Scientists proved that Drosophila has simple decision-making ability while facing contradictory visual clues, in which the mushroom bodies in its brain play a major role (Tang \& Guo 2001). At the molecular and cellular level, work on the gene expression profile of dorsal root ganglions after neuropathic pain revealed a number of factors involved in the pathogenesis which may represent future drug targets (Xiao et al. 2002). Research on opioid and tachykinin systems involved in modulation of pain transmission in the spinal cord revealed that protachykinin is essential for the modulation of sensitivity of nociceptive afferents to opioids, and that the opioid and tachykinin systems are directly linked by protachykinin/ $\delta$-opioid receptor interaction (Guan et al. 2005). As to the neuronal morphology, axondendrite polarity is essential for information flow. Work on the differential distribution of glycogen synthase kinase (GSK)-3 $\beta$ activity in the axon versus the dendrites (Jiang et al. 2005) demonstrated that there are active mechanisms for maintaining as well as establishing neuronal polarity and that GSK-3 $\beta$ plays critical roles in neuronal polarity. The result also suggested that application of GSK-3 $\beta$ inhibitors could be a novel approach to promote the generation of new axons after neural injuries. Another study on brain-derived neurotrophic factor (BDNF) showed that transient receptor potential channel activity is essential for nerve-growthcone guidance by BDNF ( $\mathrm{Li}$ et al. 2005).

The immune system, as the natural defense of our body, has been one of the hot research topics, especially the molecular mechanism of its activities. In recent years, China has achieved rapid progress in this field, thanks not only to the influx of numerous
Western-trained scientists but also to the long-standing efforts of scientists mainly trained in China. In 2004, work on the influence of lymphoid microenvironments on dendritic cells was published in Nature Immunology (Zhang et al. 2004). The work identified an important mechanism by which the microenvironment regulates immune responses. In 2005, research on multiple sclerosis (MS) revealed that copolymer-I (COP-I) induced the conversion of peripheral $\mathrm{CD} 4{ }^{+} \mathrm{CD} 25^{-}$to $\mathrm{CD} 4{ }^{+} \mathrm{CD} 25^{+}$regulatory $\mathrm{T}$ cells through the activation of transcription factor Foxp3 (Hong et al. 2005). This study provided evidence of the role and mechanism of action of COP-I in the induction of $\mathrm{CD} 4{ }^{+} \mathrm{CD} 25^{+}$ regulatory $\mathrm{T}$ cells in general and its relevance to the treatment of MS. In the same year, the same research group demonstrated, for the first time to our knowledge, that overexpression of osteopontin (OPN) in synovial $\mathrm{T}$ cells is associated with local inflammatory milieu and that OPN acts as an important mediator in amplification and perpetuation of rheumatoid synovitis (Xu et al. 2005). The study disclosed important implications for understanding the role of OPN in rheumatoid synovitis and other inflammatory conditions.

\section{(c) Systematic evolution, palaeontology, ecology and biodiversity}

Recent years have witnessed many achievements from China in systematic evolution and palaeontology. In the area of biological systematics, China has compiled a 255-volume corpus of Flora Sinica (Wu 2004), Fauna Sinica (Editorial Committee 1978) and Cryptogamica Sinica (Editorial Committee 1987), which have been highly praised by overseas peers.

Palaeontology has also seen numerous achievements, such as the discovery of the fossils of Sinornithosaurus millenii (Xu et al. 2001), four-winged dinosaurs (Xu et al. 2003) and a lot of other rare dinosaurs ( $\mathrm{Xu}$ et al. 2004; Zhang \& Zhou 2004), providing more conclusive proof for the origin of birds (Padian \& Dial 2005). Chinese scientists have also proposed a new hypothesis of birdflying function evolution - the arboreal origin hypothesis (Xu \& Zhang 2005).

The mystery of the origin of dogs has also been unveiled on the basis of in-depth investigation of canine mitochondrial DNA diversity, proving that dogs all over the world have the same genetic base and all originated from East Asia about 12000 years ago and that they spread to other parts of the world later on (Savolainen et al. 2002). With regard to the origin of humans, through analysis of special markers of 12127 male Y chromosomes, it has been proved that modern East Asians originated from Africa, just like all other peoples (Ke et al. 2001).

Since the 1920s, Chinese botanists have started a systematic research programme into plant ecology. From the early 1950 s to the late 1980s, China organized a dozen large-scale vegetation and ecology expeditions, covering most areas of the country. The scientists have identified almost all the vegetation resources in China and produced a series of regional vegetation maps. In the late 1980s, scientists established the China Ecosystem Research Network (CERN) and the China Biosphere Reserve Network and thus started nationwide ecosystem research. 
Setting-up nature reserves is a critical way for the in situ conservation of biological resources. So far, China has set up nearly 1000 nature reserves, with a total area of over 7 million ha, covering $7.5 \%$ of China's land area and projected to cover more than $8 \%$ by 2010. In 1992, China signed the 'United Nations Treaty on the Convention on Biological Diversity' and decided to build up the China Biosphere Reserve Network. Currently, there are 100 member zones in the China Biosphere Reserve Network and 27 in the International Biosphere Reserve Network. In order to solve the increasingly severe eco-environmental degradation problem, greater attention has been paid to research on ecosystem restoration and reconstruction. For example, the integrated management and demonstration zone of sandlots in Inner Mongolia showcases a new type of ecosystem restoration.

Concerning the ex situ conservation of biodiversity (e.g. botanical gardens, gene banks, etc.), 12 botanical gardens of the CAS preserve some 20000 species of vascular plants, about two-thirds of the total in China. Recently, the CAS has undertaken joint programmes with local governments in Guangdong, Hubei and Yunnan Provinces to renovate three comprehensive botanical gardens in Guangzhou, Wuhan and Xishuangbanna. In addition, a seed bank for wildlife will be built up in Kunming.

\section{CHINA'S MAJOR ACHIEVEMENTS IN BIOTECHNOLOGY AND DRUG DEVELOPMENT}

Priority areas for China's research and development $(R \& D)$ in biotechnology and biopharmaceutical research are genetic breeding of high-yield and highquality crops, transgenic technology and animal cloning, bio-reactor, gene- and protein-engineered vaccines and drugs, gene therapy and drug discovery/development.

According to the Minister of Science and Technology, Xu Guanhua (Chong 2005), China currently has 200 government-funded biotechnology laboratories. The R\&D taskforce has over 30000 personnel. More than 500 modern biotechnology enterprises with a total employment over 50000 are currently running in China. Over 20 biotechnology industrial parks were set up in Beijing, Shanghai, Guangzhou, Shenzhen and other cities in China. In the past two decades, the state has invested 15 billion RMB (US $\$ 1.8$ billion) in biotech research and development.

In addition, more than 300 universities and colleges have departments related to life science and biotechnology, and cultivate about $2000 \mathrm{PhDs}$ in life sciences each year (data from the Ministry of Education, MOE).

The total annual sales of the Chinese biotechnology industry have been witnessing a significant two-digit annual growth rate. From 2000 to 2003, the annual sales were $184.98,213.19,249.34$ and 270.3 billion RMB, respectively (Wang 2005).

\section{(a) Agricultural biotechnology}

Under its heavy demographic burden, China has demonstrated a serious commitment to the development of agricultural biotechnology. The allocation to plant biotechnology was $9.2 \%$ of the national crop research budget in 1999, up from $1.2 \%$ in 1986 (Huang et al. 2002). It was far beyond the $2-5 \%$ levels of other developing countries.

China is a world leader with respect to hybrid rice research and its application. Since the 1990s, China has maintained an annual cultivation area of 15 million hectares for hybrid rice, over $50 \%$ of the total cultivated area for rice, and the yield of hybrid rice accounts for nearly $60 \%$ of the gross rice output. Two-line hybrid rice was successfully developed in 1995. The yield of twoline hybrid rice is $5-10 \%$ more than that of three-line hybrid rice. In 2003, two-line hybrid rice was cultivated in 4.37 million hectares nationwide, with a net increase in output of 6 billion kilograms (Wang 2005).

The research programme for super hybrid rice was started in 1997, and aimed at an average unit output of 10.5 tons ha ${ }^{-1}$ in 2000 and 12 tons ha ${ }^{-1}$ in 2005 . So far, the research has made remarkable progress, generating a number of new super hybrid rice combinations with yields of 10.5 tons ha $^{-1}$ or above. Among those, 'II youming 86' demonstrated a unit output as high as 17.9 tons ha ${ }^{-1}$ in Yongsheng County of Yunnan Province in 2001, setting a world record for unit yield for rice. Since 2001, the aggregated cultivation area of super hybrid rice has reached 5.494 million hectares, producing an extra 8.141 billion kilograms of high-quality paddies (Wang 2005).

According to a survey produced by the CAS and the Chinese Academy of Agricultural Sciences (CAAS; Huang et al. 2002), Chinese scientists in plant science achieved significant progress in the synthesis, isolation and cloning of new genes and in transformations of plants with these genes. Ac/Ds transposons and T-DNA insertion methods were used to create mutagenesis pools. Rice functional genome research was actively performed in multiple laboratories throughout the country (Xue et al. 2003). To the end of 2003, 821 applications for biosafety assessment of transgenic plants were received in China and 585 were approved. At the end of 2003, the aggregate cultivation areas of insect-resistant cotton were over 2000000 ha, producing an extra net profit of 3 billion RMB. A series of new species of transgenic corn, wheat, rice, etc., with novel traits of high yield, high quality, disease and insect resistance or environmental tolerance was ready for large-scale cultivation (Wang 2005).

Encouraging achievements have also been made in animal biotechnology $R \& D$. China is leading the research on transgenic fishes and the technology is ready for large-scale commercial production. Chinese scientists have successfully cloned carp, goats, cattle and rats, and have the capability of producing medicinal proteins from transgenic animals. China's animal cloning techniques are now among the most advanced in the world.

\section{(b) Medical and pharmaceutical biotechnology}

Through years of effort, China's medical and pharmaceutical biotechnology industry has developed its primary position in the national economy. In May 2004, 27 biomedical products were approved for the market (Hu et al. 2004). In 2003, nearly 80 new biomedicines were approved on clinical trials and over 
150 in their pre-clinical development. Among the marketed biomedicines, China owns the intellectual property rights of nine (Wang 2005). Now China has the ability to produce 8 out of the top 10 biomedical bestsellers in the world. Market share of biotechnological medicines has been rising continually. Interferon $\alpha 1 \mathrm{~b}$, the first China-made recombinant medicine, has a $60 \%$ domestic market penetration.

The therapeutic hepatitis $\mathrm{B}$ vaccine, gene-engineered HBV antigen-antibody complex, was approved to go into clinical trial in June 2003 and has received domestic and international patents (Wang 2005). The technology transfer of artificial blood substitutes has been going smoothly. Pilot production bases have been set up and numerous batches of products have met the quality control criteria.

A shift from imitation to innovation in biotechnology medicines is underway in China. Research into monoclonal antibodies or antibody derivatives for diagnosis and targeting therapy is healthy and active. Gene therapy using an adenovirus vector-base P53 injection for head and neck cancer in combination with chemotherapy has got governmental approval - a first for the world (Wang 2005). A series of breakthroughs and major progress have been made in fields such as cancer immune therapy, anti-angiogenesis therapy and tissue engineering research, etc.

In the first half of 2005, four biomedicine enterprises, ranked in the top 100 pharmaceutical companies in China, registered 2.96 billion yuan in sales revenue and made profits amounting to $47.7 \%$ of the total biomedicine sector (Asia Times 2005). It is remarkable to see that the annual sales of the biomedicine industry increased from US $\$ 200$ million in 1996 to US $\$ 3$ billion in 2005. Now, there are over 160 listed companies involved in medical biotechnology (China National Center for Biotechnology Development 2004). However, only four to five biomedicine enterprises are in the top 100 pharmaceutical companies in China. There is still a long road ahead for the biomedical industry in China.

\section{(c) Drug discovery/development}

Through focused research programmes, several novel drugs have been developed. For example, artemether, a novel anti-malaria drug based on artemisinin and developed in China, has been included in the World Health Organization (WHO) Model List of Essential Medicines and is widely used in the developing countries (Li \& Wu 1998). Sodium dimercaptosuccinate, an antidote used in China against heavy metal poisoning, has also been approved by the Federal Drug Agency (FDA) and is used in the United States for lead poisoning. Huperzine A, a novel alkaloid isolated from a Chinese herbal medicine, was demonstrated to be effective in improving memory deficiencies in aged people and Alzheimer's disease patients (Jiang et al. 2003). With support from the Ministry of Science and Technology (MOST), the CAS, the Ministry of Health $(\mathrm{MOH})$, the State Food and Drug Administration (SFDA) and Shanghai Municipal Government, the National Center for Drug Screening was set up in Shanghai in 1997. The Center was mainly devoted to drug target identification and validation, combinatorial chemistry, high-throughput screening and computeraided drug design. Since its establishment, more than 200 screening assays have been built up and over 500 novel lead compounds have been found. TCM has been used in China for thousands of years. To increase the recognition of TCM in the international market, China has recently made a great effort to speed up the modernization of TCM. State-of-the-art techniques and equipment have been introduced to develop and standardize TCM production. Recently, several TCM drugs have entered the international market.

\section{CHINA'S STRATEGIES TO STRENGTHEN THE DEVELOPMENT OF LIFE SCIENCE AND BIOTECHNOLOGY}

Despite breakthroughs achieved in key areas, life sciences and biotechnology in China are still facing a number of problems. Insufficient talent and lack of original innovation, a relatively weak infrastructure, a poor coordination mechanism leading to unnecessarily duplicated project layout, scant $\mathrm{R} \& \mathrm{D}$ investment from enterprise, weak translational research between scientific research and industrial application, and a growing legal system lagging behind the development of science and technology have all taken a heavy toll on efficiency. What is more, output is relatively low when compared with other science and technology disciplines, which can be well illustrated by the percentage of papers in life science and biotechnology among all scientific papers published during 1992-2001. According to a statistical study of scientific papers during this period, papers in life science and biotechnology accounted for $27.1 \%$ of all scientific papers worldwide, while in China only $11.4 \%$ was from this field (figure $1 a, b$ ). This urges that life science and biotechnology must be further strengthened in China. Fortunately, not only the Chinese scientific community but also the policy makers have fully recognized the significance of this field. In his opening address at the Fourth National Congress of Science and Technology on 9 January 2006, Chinese President, Hu Jintao, pointed out that life science and biotechnology will play a key role in improving the quality of human life. He said that 'Biotechnology is the priority of high-tech industries by which China will try to catch up with the developed countries, and China will strengthen the application of biotechnology to agriculture, industry, population and health'. To meet the challenge of a new era of life science and biotechnology, Chinese policy makers, advised by the scientific community, have implemented a series of effective strategies for capacity building in recent years.

(a) Coordination of efforts at administrative level The creation of a National Biotech Leadership Committee in June 2004 symbolized the start of a new era for life science and biotechnology development in China. The administration departments for biotechnology and bioindustry in China are the MOST, the State Development and Reform Commission (SDRC), the National Natural Science Foundation of China (NSFC), the MOE, the MOH, the MOA, etc. The MOST and the NSFC are taking the responsibility of supporting basic research. High-tech R\&D and industrialization, as 


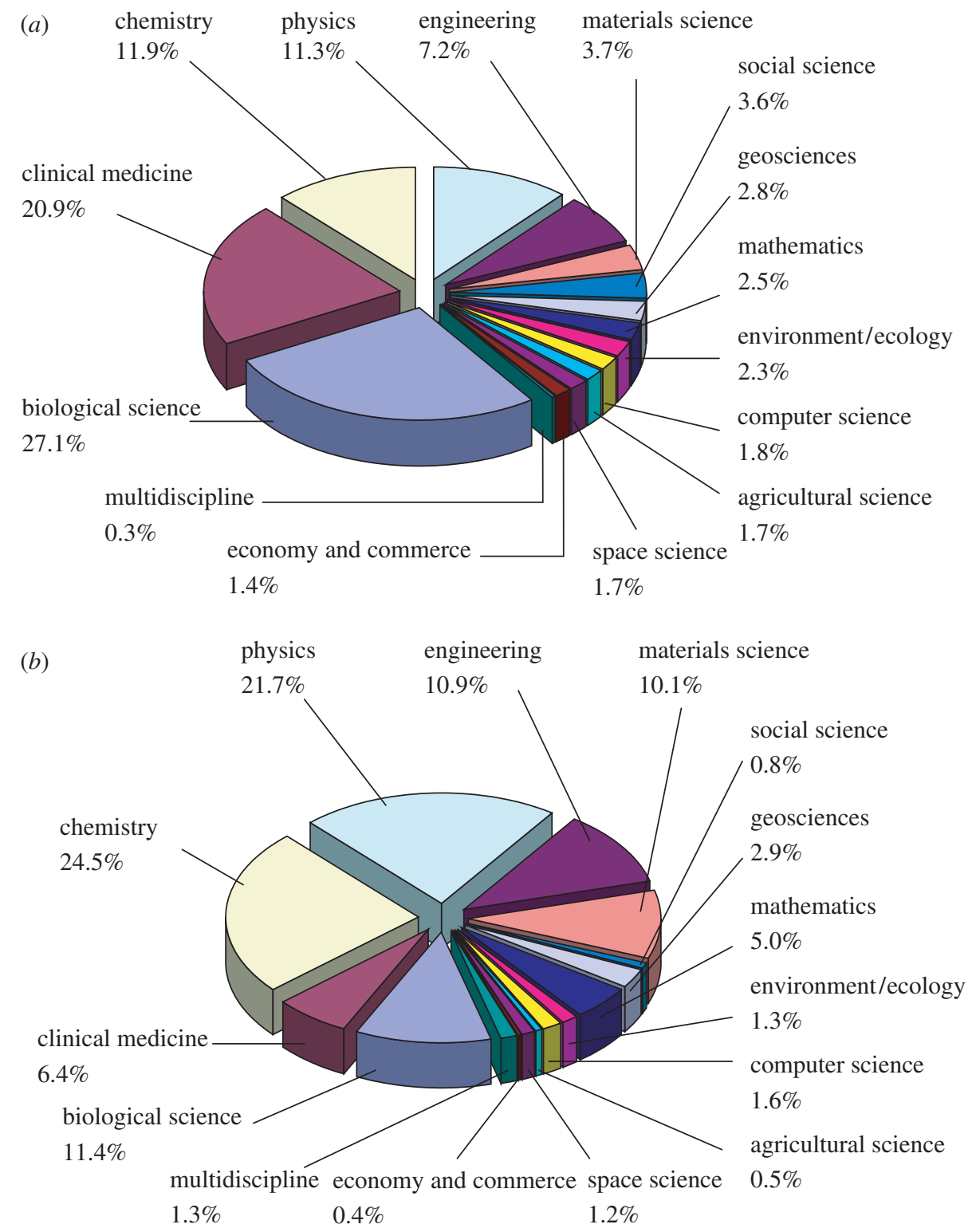

Figure 1. Contribution of scientific papers by discipline, worldwide (a) and in China (b) during 1992-2001.

well as certification of bio-enterprises, are under the administration of the MOST. The SDRC is responsible for facilitating the industrialization of biotechnology and policy-making related to bioindustry. China National Center for Biotechnology Development is an institution under the MOST, which is in charge of organizing and implementing work in biotechnology research and development.

\section{(b) Building-up of sound research} and funding systems

China's modern life-science research has maintained a very close relationship with medicine, agronomy and the utilization of biological resources. China's biotechnology research did not get started until the mid1970s. Modern research into life sciences and biotechnology in China involves institutes and facilities affiliated with the CAS; research universities, institutes and units affiliated with different line departments (e.g. the Chinese Academy of Medical Sciences under the $\mathrm{MOH}$ and the CAAS under the MOA); and local scientific organizations. Within the CAS, the country's only multidisciplinary research institution for natural science and high-tech development, there are 6000 researchers, 24 institutes, 13 research centres, 26 key laboratories, 12 botanical gardens, 18 herbaria, 9 databases of herbarium and dozens of ecosystem field stations involved in life sciences and biotechnology R\&D. The institutions can be grouped into four bases: Beijing base, concentrating on agricultural and environmental issues; Shanghai base, focusing on $\mathrm{R} \& \mathrm{D}$ related to population and human health; southwestern base in Chengdu, Xining, Kunming and Xishuangbannan, concerned with biodiversity conservation; and midsouth base in Wuhan and Guangzhou, focusing on biosafety, ecosystem restoration and biotechnology (figure 2). Owing to the efforts of the Chinese government over many years, a state key laboratory system in some of the key areas of life sciences is in place across different institutions and universities, in parallel with the National Engineering Research Center system in some of the critical areas of biotechnology. In addition, there are schools with life sciences or bioengineering-related majors in many comprehensive universities. 


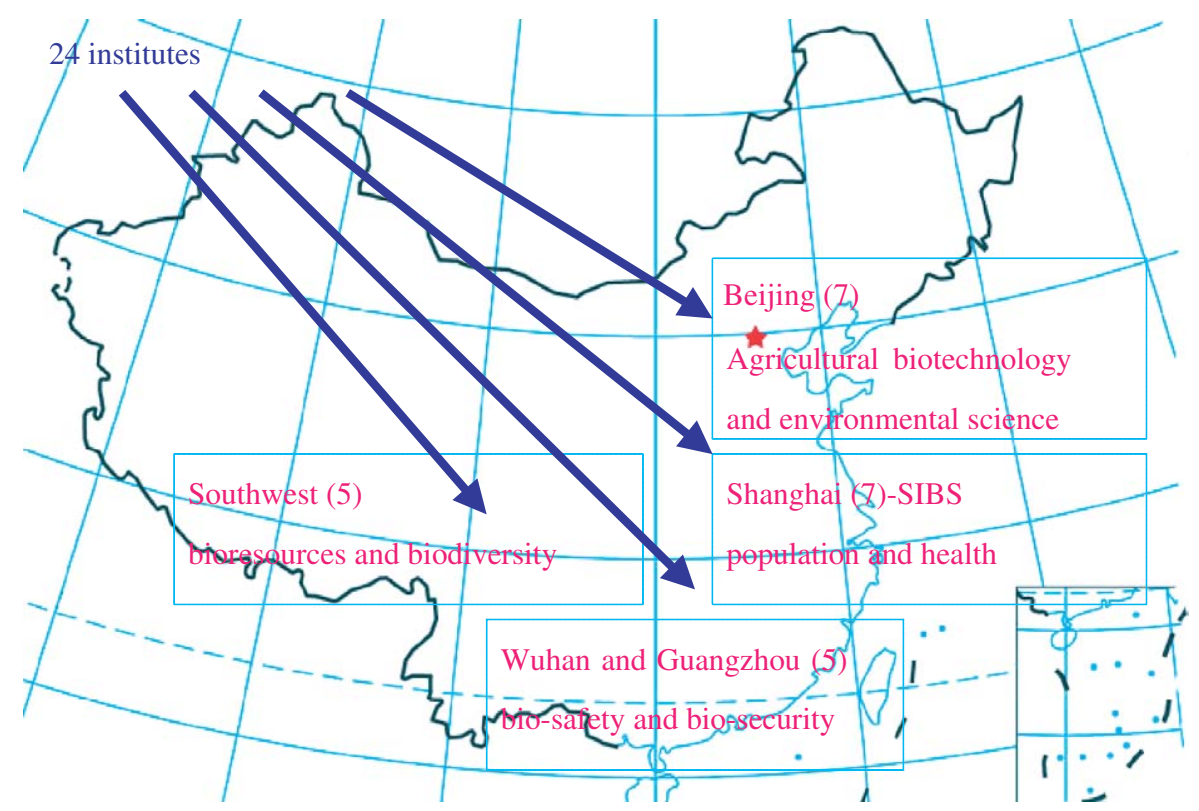

Figure 2. Life science research at the Chinese Academy of Sciences, grouped into four bases. SIBS, Shanghai Institutes for Biological Science.

Table 1. Gross domestic expenditure on R\&D in China.

\begin{tabular}{|c|c|c|c|c|c|c|c|c|c|}
\hline & 1997 & 1998 & 1999 & 2000 & 2001 & 2002 & 2003 & 2004 & expected for $2010^{a}$ \\
\hline $\begin{array}{l}\text { gross domestic expenditure on } \\
\text { R\&D (100 million yuan) }\end{array}$ & 509.2 & 551.1 & 678.9 & 895.7 & 1042.5 & 1287.6 & 1539.6 & 1843 & $\begin{array}{r}4552(2.47 \text { times of } \\
\text { the sum of } 2004)\end{array}$ \\
\hline as a percentage of GDP & 0.64 & 0.69 & 0.83 & 1.01 & 1.09 & 1.23 & 1.31 & 1.35 & 2.0 \\
\hline $\begin{array}{l}\text { government } S \& T \text { appropria- } \\
\text { tion (100 million yuan) }\end{array}$ & 408.9 & 438.6 & 543.9 & 575.6 & 703.3 & 816.2 & 975.5 & - & \\
\hline
\end{tabular}

${ }^{a}$ According to an annual GDP growth rate of $9 \%$ over 2004-2010.

With years of practice, a sound funding system has also been established. There are a number of funding sources for research in life sciences and for the industrialization of biotechnology in China. Major funding agencies are the MOST, the NSFC, the CAS, other ministries, local governments and concerned enterprises. In 1986, life sciences and biotechnology were listed in the National High Technology Research and Development Programme (or 863 Programme) as key areas to be funded, which led to a golden period of development for biotechnology in China. The National Key Basic Research Development Programme (or 973 Programme), initiated in 1998, also included agriculture, population/health and resources/environment as areas of priority. The support of the Department of Life Sciences of the NSFC accounts for one-third of the Foundation's total funding in terms of both the number of funded projects and the amount of funding. The funding in life sciences and biotechnology from the CAS in 2004 accounted for $15.6 \%$ of its total budget. Through the above main funding channels, the gross domestic expenditure on $\mathrm{R} \& \mathrm{D}$ in science and technology has jumped from 50.92 billion RMB $(0.64 \%$ of GDP) in 1997 to 184.3 billion RMB in 2004 (1.35\% of GDP) and is expected to be 455.2 billion RMB in 2010 (2.0\% of GDP; table 1). Meanwhile, about $20 \%$ of the total science and technology investment goes to $\mathrm{R} \& \mathrm{D}$ in life science and biotechnology.

\section{(c) Recruitment of talent}

A talent strategy is a key issue for developing life science and biotechnology in China. At the opening address of the Fourth National Conference of Science and Technology, President $\mathrm{Hu}$ of China outlined the strategy: 'China will train world first-class scientists, especially young and middle-aged scientists, based at national key scientific research projects and international scientific cooperation projects. An incentive mechanism should be instigated to increase the efficiency of innovation and provide more chances for young talented people. China will admit more talented people from overseas and attract overseas Chinese graduates back to start businesses in China'. To attract more talented people to devote themselves to this area, administrative departments at different levels have adopted various projects, such as the 'Hundred-Talent Project' of the CAS, the 'National Outstanding Young Scholar Project' of the NSFC and the 'Cheung Kong Scholar Project' of the MOE. At local government level, Shanghai, for example, has set up the 'Morning Star Project' and 'Dawning Project'. These projects provide a good guarantee of research work for Chinese life scientists, especially young talent, and at the same time have attracted many talented individuals to return to China after receiving good training abroad. Presently, young talent has become the mainstay in promoting the advancement of science and technology in China. 
Table 2. CAS publications in Nature, Nature series journals and Science. (In the first half of 2005, four papers by scientists from the CAS were published in Cell. A large number of papers were published in high-level international journals with an $I F>10$ over the past 5 years.)

\begin{tabular}{lccl}
\hline year & CAS total & LS/BT & percentage (\%) \\
\hline 2001 & 30 & 12 & 40.0 \\
2002 & 31 & 13 & 41.9 \\
2003 & 28 & 15 & 53.6 \\
2004 & 45 & 23 & 51.1 \\
2005 (till June) & 21 & 7 & 33.3 \\
total & 155 & 70 & 45.1 \\
\hline
\end{tabular}

${ }^{\text {a }}$ LS/BT, life sciences/biotechnology.

During the first 10-year trial (from 1994 to 2004), there were 1069 awardees of the 'Hundred-Talent Project' with a total funding of over US $\$ 250$ million sponsored by the CAS. Among them, 14 were elected as new members of the CAS, 13 were appointed as chief scientists of the National Key Basic Research Programmes (973 Programme) and 57 were chosen to head the High-tech Research and Development Programmes of China (863 Programme). In recent years, the 'talent strategy' has started to bear fruit, exemplified by the number and level of scientific publications. For example, at the CAS, 12 papers on life science and biotechnology were published in Nature, Nature series and Science in 2001, and the number increased to 23 in 2004 (table 2). In the first half of 2005, four papers by scientists from the CAS were published in Cell. A large number of papers were published in high-level international journals with a high impact factor (IF greater than 5) over recent years. The establishment of the National Institute of Biological Sciences (NIBS) in Beijing is a further example of China's success in attracting Chinese life scientists back from overseas to pursue world-class research at home.

\section{(d) Attachment of importance to biosafetyl biosecurity and bioethics issues}

When compared with other scientific areas, life sciences and biotechnology have the most impact on humankind and its future. Therefore, the biosafety/ biosecurity and bioethics issues derived from the development of life sciences and biotechnology are drawing wide attention from governments, scientists and even the ordinary public in many countries. A worldwide debate is well underway. It is no wonder that peoples of different countries, nationalities, religions and intellectual levels hold different views on the bioethics issue. Nevertheless, there should be common ground on a number of fundamental points, such as the protection of human and national dignity, the protection of gene resources and ecological environment, and ensuring food and water safety, among others.

The Chinese government has paid great attention to the protection of genetic resources and to biosafety as well as observation of bioethical rules. Since 1993, about 10 laws or regulations have been promulgated on biosafety. In 1993, the former State Science and Technology Commission issued a 'Safety Administration Regulation on Genetic Engineering' (State
Science and Technology Commission P. R. C. 1993), followed by the 'Safety Administration Implementation Regulation on Agricultural Biological Genetic Engineering' issued by the MOA in 1996 (Ministry of Agriculture, P. R. C. 1996). The MOA set up the Biosafety of Agricultural Genetic Engineering Administration Office in the same year, which started their procedures for assessment and approval of the safe release of transgenic beings in 1997. The State Council issued 'Regulations on Administration of Agricultural Genetically Modified Organisms Safety' in 2001 (State Council, P. R. C. 2001). The MOA also issued three legal documents as 'Implementation Regulations on Safety Assessment of Agricultural Genetically Modified Organisms' (Ministry of Agriculture, P. R. C. 2002b), 'Implementation Regulations on the Safety of Import of Agricultural Genetically Modified Organisms' (Ministry of Agriculture P. R. C. 2002c) and 'Implementation Regulations on Labelling of Agricultural Genetically Modified Organisms' (Ministry of Agriculture P. R. C. 2002a) in 2002. The MOST and the $\mathrm{MOH}$ jointly worked out 'Interim Measures for the Administration of the Human Genetic Resource' (Ministry of Science and Technology \& Ministry of Health P. R. C. 1998). The State Environmental Protection Administration (SEPA) organized and worked out a series of documents including the 'National Biosafety Frameworks of China' (State Environmental Protection Administration 2000). Since 2002, some government administrative departments, such as the MOST, the SEPA, the MOA and the $\mathrm{MOH}$, have issued a number of new biosafety regulations or related laws, significantly improving the management of this essential issue.

With regard to bioethics, the Chinese government maintains that, while investigating and applying achievements in life sciences and biotechnology, the principles of 'good-will, harmless, informed consent, informed and fair choice' should be observed. Presently, there are institutes and persons engaged in bioethics in Beijing, Shanghai, Guangzhou, Chengdu, Nanjing, Daliang, Xian, etc. In recent years, Chinese researchers of bioethics have been tracking and studying the cuttingedge issues in international bioethics, including human reproductive cloning, embryonic stem cell research, the Human Genome Project, genetically modified foods (GM food), etc. They actively participate in the relevant activities carried out by the United Nations Educational, Scientific and Cultural Organization (UNESCO), the WHO, the International Human Genome Organization, the International Bioethics Society and so on, including worldwide discussions on 'health purpose'. In addition, China has carried out various international academic activities on bioethics, such as seminars by the Asia Bioethics Society and various multilateral or bilateral symposia.

As applied standard ethics, bioethics should be reflected in various rules and standards, so that people have a framework to follow and know what they should and should not do. Important literature, such as the Nuremberg Code, Declaration of Helsinki, the International Ethical Guidelines for Biomedical Researches Involving Human Subjects, Universal Declaration on the Human Genome and Human Rights, Declaration 
on Principled Behaviour for Genetic Research Morality, etc., was introduced as the fundamental reference and for guidance. Promoted by the Chinese biomedical science community, China has also formulated some standards on bioethics adapted to national conditions and needs (Doring 2004). Those include 'Interim Measures for the Administration of Human Genetic Resources' (1998), 'Measures for Ethical Review in Biomedical Researches Involving Human Subjects' (1998), 'Good Clinical Practice' (1999), 'Ethical Rules for (Human) Medical Assisted Reproduction Technology and Human Sperm Bank' (2001) and 'Ethical Guidance on Human Embryonic Stem Cell Research' (2003), etc.

\section{(e) Protection of intellectual property rights}

China supports innovative activities via key science and technology programmes and will step up efforts for the protection of intellectual property rights by improving the protection system and related laws and regulations, while severely cracking down on violations according to law. Foreign patents and intellectual property rights are respected and protected based on international norms and commitments made by China on entry to the World Trade Organisation (WTO), and the use of China's own patents through equal and mutually beneficial international cooperation is also expected.

\section{(f) Establishment of a standard system for the biotechnology industry}

In order to meet the demands of bioindustry, great attention needs to be given to the standardization and quality control of new products and technologies. A product standard and production procedure will be developed. Meanwhile, the existing biotechnology R\&D and industrialization system will be upgraded, and the international competitiveness of China's bioindustry will be improved by employing international standards of good practice for laboratory, manufacturing and clinical situations (GLP, GMP and GCP).

\section{(g) Establishment of close international cooperation}

Along with the globalization of the economy, scientific collaboration has become widespread in research and development. As always, China welcomes the International Science and Technology Cooperation and exchange based on mutual benefit, results sharing, intellectual property right protection and respect for international norms. China has signed science and technology cooperation agreements with 95 countries and conducted joint activities in various forms with more than 150 countries. Technology innovation, particularly in the field of life science and biotechnology, is a priority of the International Science and Technology Cooperation. China has participated in several international 'big science' cooperative programmes such as the Human Genome Programme (HGP; Lander et al. 2001), International HapMap Project (The International HapMap Consortium 2003) and International Rice Genome Sequencing Project (IRGSP; International Rice Genome Sequencing Project 2005) and plays a leading role in the Human Liver Proteome Project (HLPP; He 2005).

\section{PERSPECTIVES}

Along with continued rapid economic growth over the past 20 years and the emergence of genomics, China's life science community has made a historical stride forward. However, there is still a long way to go to close the gap between the overall research level in China and the advanced world level. Therefore, a better balance between science frontiers and the needs of the country is warranted.

On 9 February 2006, the State Council issued the National Guidelines for Medium- and Long-term Plans for Science and Technology Development from 2006 to 2020 (State Council, P. R. C. 2006). The guidelines emphasize the move from tracking after and imitating to innovation, from individual technology-oriented R\&D to integrated innovation for key products and emerging industries, and from research institute-oriented reform to the construction of a national innovation system. It gives priority to technical development in 11 major sectors, including energy, water resources, environment, agriculture, and population and human health, in the coming 15 years, in order to solve the major problems bottlenecking development of the social economy in China. In the next 15 years, China will give top priority to research in the areas of protein science, quantum information science, nanoscience and developmental and reproductive biology as stated in the guidelines. The guidelines set the proportion of R\&D expenditure at $2 \%$ of the gross domestic product by 2010 , and over $2.5 \%$ by 2020 .

In order to tackle the major problems constraining the development of the social economy, such as energy shortages, environmental protection, disease control and prevention and public security, life science and biotechnology have been chosen as one of the research and development priorities by the Chinese central government. With the increasing support of the government and the combined efforts of the Chinese life science community and biotechnology industry, China is expecting progress in life science and biotechnology to take a leap forward in the next 15 years.

Through the joint efforts of scientific communities all over the world, in dealing with common challenges in life sciences and biotechnology, it is hoped that the whole of humankind can enjoy a better life and advance together along a common developmental road.

\section{REFERENCES}

Asia Times, 2005 Pharma sector grows briskly in first half of 2005. Asia Times. See http://www.atimes.com/atimes/ China_Business/GI21Cb02.html.

Chen, L. 1982 Topological structure in visual perception. Science 218, 699-700. (doi:10.1126/science.7134969)

Chen, Y.-H. et al. 2003 a KCNQ1 Gain-of-function mutation in familial atrial fibrillation. Science 299, 251-254. (doi: 10. 1126/science.1077771)

Chen, Y. et al. $2003 \mathrm{~b}$ Embryonic stem cells generated by nuclear transfer of human somatic nuclei into rabbit oocytes. Cell Res. 13, 251-263. (doi:10.1038/sj.cr.7290170)

China National Center for Biotechnology Development, 2004 Biotechnological medicines. See http://www.cncbd. org.cn/chanye/chanye/yao.html. [In Chinese.]

Chong, W. 2005 Biotech prepares for rapid expansion. China Daily. See http://www.chinadaily.com.cn/english/ doc/2005-09/15/content_477984.htm. 
Doring, O. 2004 Chinese researchers promote biomedical regulations: what are the motives of the biopolitical dawn in China and where are they heading? Kennedy Inst. Ethics F. 14, 39-46. (doi:10.1353/ken.2004.0014)

Du, W. et al. 2001 Confirmation of susceptibility gene loci on chromosome 1 in northern China Han families with type 2 diabetes. Chin. Med. F. (Engl) 114, 876-878.

Editorial Committee 1978 Fauna Sinica. Beijing, China: Science Press. See http://www.sciencep.com/gb/content/ 2001-11/19/content_367.htm.

Editorial Committee 1987 Cryptogamica Sinica. Beijing, China: Science Press. See http://www.sciencep.com/gb/ content/2006-03/28/content_10871.htm.

Feng, B. J. et al. $2002 a$ Genome-wide scan for familial nasopharyngeal carcinoma reveals evidence of linkage to chromosome 4. Nat. Genet. 31, 395-399.

Feng, Q. et al. $2002 b$ Sequence and analysis of rice chromosome 4. Nature 420, 316-320. (doi:10.1038/nature01183)

Gao, H., Sun, Y., Wu, Y., Luan, B., Wang, Y., Qu, B. \& Pei, G. 2004 Identification of beta-arrestin2 as a G proteincoupled receptor-stimulated regulator of NF-kappaB pathways. Mol. Cell 14, 303-317. (doi:10.1016/S10972765(04)00216-3)

Guan, J. S. et al. 2005 Interaction with vesicle luminal protachykinin regulates surface expression of delta-opioid receptors and opioid analgesia. Cell 122, 619-631. (doi:10. 1016/j.cell.2005.06.010)

He, F. 2005 Human liver proteome project: plan, progress, and perspectives. Mol. Cell. Proteomics 4, 1841-1848. (doi:10.1074/mcp.R500013-MCP200)

He, F. 2006 Proteomics in China. Proteomics 6, 397-403. (doi:10.1002/pmic.200690008)

Hong, J., Li, N., Zhang, X., Zheng, B. \& Zhang, J. Z. 2005 Induction of $\mathrm{CD} 4{ }^{+} \mathrm{CD} 25^{+}$regulatory $\mathrm{T}$ cells by copolymer-I through activation of transcription factor Foxp3. Proc. Natl Acad. Sci. USA 102, 6449-6454. (doi:10.1073/ pnas.0502187102)

$\mathrm{Hu}, \mathrm{X}$., Chen, H., Tang, C. \& Ma, Q. 2004 Comparison of approved biomedicines among USA, EU and China. China Biotechnol. 24, 95-101.

Huang, J., Rozelle, S., Pray, C. \& Wang, Q. 2002 Plant biotechnology in China. Science 295, 674-676. (doi:10. 1126/science.1067226)

International Rice Genome Sequencing Project 2005 The map-based sequence of the rice genome. Nature 436, 793-800. (doi:10.1038/nature03895)

Jiang, Z. 2000 Science in China. Science 288, 2317. (doi:10. 1126/science.288.5475.2317)

Jiang, H., Luo, X. \& Bai, D. 2003 Progress in clinical, pharmacological, chemical and structural biological studies of huperzine A: a drug of traditional Chinese medicine origin for the treatment of Alzheimer's disease. Curr. Med. Chem. 10, 2231-2252. (doi:10.2174/092986 7033456747)

Jiang, H., Guo, W., Liang, X. \& Rao, Y. 2005 Both the establishment and the maintenance of neuronal polarity require active mechanisms: critical roles of GSK-3beta and its upstream regulators. Cell 120, 123-135.

Kang, J. et al. 2005 A nuclear function of beta-arrestin1 in GPCR signaling: regulation of histone acetylation and gene transcription. Cell 123, 833-847. (doi:10.1016/j.cell. 2005.09.011)

Ke, Y. et al. 2001 African origin of modern humans in East Asia: a tale of 12000 Y chromosomes. Science 292, 1151-1153. (doi:10.1126/science.1060011)

Kung, Y. T., Du, Y. C., Huang, W. T., Chen, C. C. \& Ke, L. T. 1965 Total synthesis of crystalline bovine insulin. Sci. Sin. 14, 1710-1716.
Lander, E. S. et al. 2001 Initial sequencing and analysis of the human genome. Nature 409, 860-921. (doi:10.1038/ 35057062)

Li, Y. \& Wu, Y. L. 1998 How Chinese scientists discovered qinghaosu (artemisinin) and developed its derivatives. What are the future perspectives? Med. Trop. (Mars) 58, 9-12.

Li, P., Chan, H. C., He, B., So, S. C., Chung, Y. W., Shang, Q., Zhang, Y.-D. \& Zhang, Y.-L. 2001 An antimicrobial peptide gene found in the male reproductive system of rats. Science 291, 1783-1785. (doi:10.1126/science.1056545)

$\mathrm{Li}, \mathrm{X}$. et al. 2003 Control of tillering in rice. Nature 422, 618-621. (doi:10.1038/nature01518)

Li, Y., Jia, Y. C., Cui, K., Li, N., Zheng, Z. Y., Wang, Y. Z. \& Yuan, X. B. 2005 Essential role of TRPC channels in the guidance of nerve growth cones by brain-derived neurotrophic factor. Nature 434, 894-898. (doi:10.1038/nature 03477)

Luo, T. H., Zhao, Y., Li, G., Yuan, W. T., Zhao, J. J., Chen, J. L., Huang, W. \& Luo, M. 2001 A genome-wide search for type II diabetes susceptibility genes in Chinese Hans. Diabetologia 44, 501-506. (doi:10.1007/s001250051649)

Mcgovern, P. E. et al. 2004 Fermented beverages of pre- and proto-historic China. Proc. Natl Acad. Sci. USA 101, 17 593-17 598. (doi:10.1073/pnas.0407921102)

Ministry of Agriculture People's Republic of China 1996 Safety administration implementation regulation on agricultural biological genetic engineering. See http://www.sepa.gov.cn/BCHMEN/2173063 78602020864/20040116/1045169.shtml.

Ministry of Agriculture People's Republic of China 2002a Implementation regulations on labeling of agricultural genetically modified organisms. See http://www.biosafety.gov.cn/image20010518/5423.pdf.

Ministry of Agriculture People's Republic of China $2002 b$ Implementation regulations on safety assessment of agricultural genetically modified organisms. See http:// www.biosafety.gov.cn/image20010518/5421.pdf.

Ministry of Agriculture People's Republic of China 2002c Implementation regulations on the safety of import of agricultural genetically modified organisms. See http:// www.biosafety.gov.cn/image20010518/5422.pdf.

Ministry of Science and Technology \& Ministry of Health People's Republic of China 1998 Interim measures for the administration of human genetic resources. See http://www.ocgr.org/Cn/laws/042315022302.aspx.

Padian, K. \& Dial, K. P. 2005 Origin of flight: could "fourwinged" dinosaurs fly? Nature 438, E3. (doi:10.1038/ nature04354)

Ren, S. X. et al. 2003 Unique physiological and pathogenic features of Leptospira interrogans revealed by wholegenome sequencing. Nature 422, 888-893. (doi:10.1038/ nature01597)

Savolainen, P., Zhang, Y.-P., Luo, J., Lundeberg, J. \& Leitner, T. 2002 Genetic evidence for an east Asian origin of domestic dogs. Science 298, 1610-1613. (doi:10.1126/ science.1073906)

Song, H.-D. et al. 2005 Cross-host evolution of severe acute respiratory syndrome coronavirus in palm civet and human. Proc. Natl Acad. Sci. 102, 2430-2435. (doi:10. 1073/pnas.0409608102)

State Council People's Republic of China 2001 Regulations on administration of agricultural genetically modified organisms safety. See http://english.gov.cn/2005-08/24/ content_179502.htm.

State Council People's Republic of China 2006 Guidelines on national medium- and long-term program for science and technology development (2006-2020). See http:/gh.most. gov.cn/zcq/ShowContent.jsp?db $=$ KJGHGZDT\&id $=163$. 
State Environmental Protection Administration 2000 National biosafety frameworks of China. Beijing, China: China Environment Science Press.

State Science and Technology Commission People's Republic of China 1993 Safety administration regulation on genetic engineering. See http://www.sepa.gov.cn/BCHM EN/217306378602020864/20040116/1045170.shtml.

Tang, S. \& Guo, A. 2001 Choice behavior of Drosophila facing contradictory visual cues. Science 294, 1543-1547. (doi:10.1126/science.1058237)

The International HapMap Consortium 2003 The International HapMap project. Nature 426, 789-796. (doi:10. 1038/nature02168)

The Peking Insulin Structure Research Group 1974 Studies on the insulin crystal structure: the molecule at $1.8 \mathrm{~A}$ resolution. Sci. Sin. 17, 752-778.

Wang, C. C. 2002 Protein disulfide isomerase as an enzyme and a chaperone in protein folding. Methods Enzymol. 348, 66-75.

Wang, H. G. 2005 Report of biotechnology development in China. Beijing, China: China Agricultural Press.

Wang, Z. Y. \& Chen, Z. 2000 Differentiation and apoptosis induction therapy in acute promyelocytic leukaemia. Lancet Oncol. 1, 101-106. (doi:10.1016/S1470-2045(00) 00017-6)

Wu, Z.-Y. 2004 Flora Sinica. Beijing, China: Science Press. See http://flora.huh.harvard.edu/china/.

Xia, J. H. et al. 1998 Mutations in the gene encoding gap junction protein beta- 3 associated with autosomal dominant hearing impairment. Nat. Genet. 20, 370-373. (doi: $10.1038 / 3845$ )

Xiao, H.-S. et al. 2002 Identification of gene expression profile of dorsal root ganglion in the rat peripheral axotomy model of neuropathic pain. Proc. Natl Acad. Sci. USA 99, 8360-8365. (doi:10.1073/pnas.122231899)

$\mathrm{Xu}, \mathrm{X}$. \& Zhang, F. 2005 A new maniraptoran dinosaur from China with long feathers on the metatarsus. Naturwissenschaften 92, 173-177. (doi:10.1007/s00114004-0604-y)
Xu, X. et al. 1999 An extreme-sib-pair genome scan for genes regulating blood pressure. Am. F. Hum. Genet. 64, 1694-1701. (doi:10.1086/302405)

Xu, X., Zhou, Z.-H. \& Prum, R. O. 2001 Branched integumental structures in Sinornithosaurus and the origin of feathers. Nature 410, 200-204. (doi:10.1038/35065589)

Xu, X., Zhou, Z., Wang, X., Kuang, X., Zhang, F. \& Du, X. 2003 Four-winged dinosaurs from China. Nature 421, 335-340. (doi:10.1038/nature01342)

Xu, X., Norell, M. A., Kuang, X, Wang, X., Zhao, Q. \& Jia, C. 2004 Basal tyrannosauroids from China and evidence for protofeathers in tyrannosauroids. Nature 431, 680-684. (doi:10.1038/nature02855)

$\mathrm{Xu}$, G. et al. 2005 Role of osteopontin in amplification and perpetuation of rheumatoid synovitis. F. Clin. Invest. 115, 1060-1067. (doi:10.1172/JCI200523273)

Xue, Y., Li, J. \& Xu, Z. 2003 Recent highlights of the China Rice Functional Genomics Program. Trends Genet. 19, 390-394. (doi:10.1016/S0168-9525(03)00141-0)

Yang, H. et al. 2003 The crystal structures of severe acute respiratory syndrome virus main protease and its complex with an inhibitor. Proc. Natl Acad. Sci. USA 100, 13 190-13 195. (doi:10.1073/pnas.1835675100)

Yu, J. et al. 2002 A draft sequence of the rice genome (Oryza sativa L. ssp. indica). Science 296, 79-92. (doi:10.1126/ science.1068037)

Zhang, F. \& Zhou, Z. 2004 Palaeontology leg feathers in an Early Cretaceous bird. Nature 431, 925. (doi:10.1038/ 431925a)

Zhang, M. et al. 2004 Splenic stroma drives mature dendritic cells to differentiate into regulatory dendritic cells. Nat. Immunol. 5, 1124-1133. (doi:10.1038/ni1130)

Zhu, D. L. et al. 2001 Linkage of hypertension to chromosome 2q14-q23 in Chinese families. F. Hypertens. 19, 55-61. (doi:10.1097/00004872-200101000-00008)

Zhuo, Y., Zhou, T. G., Rao, H. Y., Wang, J. J., Meng, M., Chen, M., Zhou, C. \& Chen, L. 2003 Contributions of the visual ventral pathway to long-range apparent motion. Science 299, 417-420. (doi:10.1126/science.1077091) 